\title{
Cenário Surdo e seus lugares de fala na Revista Educação Especial: uma análise por Redes Sociais
}

\section{Deaf Scenery and its speaking places in the Revista Educação Especial: an analysis by Social Networks}

\section{Escenario Surdo y sus lugares de habla la Revista Educação Especial: un análisis por Redes Sociales}

\section{* Renata Barbosa Dionysio}

Professora doutoranda pela Universidade Federal do Tocantins (UFT). Araguaína, Tocantins, Brasil. renatadionysio@uft.edu.br

\section{** Álvaro Chrispino}

Doutor em Educação pela UFRJ. Professor do CEFET/RJ. Rio de Janeiro, Rio de Janeiro, Brasil.

alvaro.chrispino@gmail.com

Recebido: 13 de março de 2018

Aprovado: 30 de Julho de 2018

\section{RESUMO}

As políticas públicas educacionais têm um papel fundamental na construção e concretização de cenários onde a educação seja valorizada e tenha como foco central o aluno e seus direitos como sujeito social e, nesta perspectiva, é importante conhecer as discussões a respeito da Educação de Surdos. O presente artigo tem como objetivo caracterizar os estudos a respeito da surdez e do surdo na Revista Educação Especial no período de 2000 a 2017. Para isso, dentre os 569 artigos que estão disponibilizados no site da revista foram selecionados 60 artigos que tratam da temática (Apêndice 1). Realizaramse estudos por meio de redes sociais para estabelecer interrelações entre palavras-chave, autores, obras mais referenciadas e também publicações por ano. As reflexões feitas a partir das análises mostram a importância de realizar estudos que posicionem o surdo como sujeito social dentro de uma perspectiva sócio, histórico-cultural onde o bilinguismo tem 0 papel de possibilitar a comunicação entre os indivíduos e também seu desenvolvimento cultural. A análise permitiu perceber que o tema materiais didáticos é um dos mais presentes quando se refere à educação de surdos, assim como inclusão e libras. Percebeuse também que o conjunto de leis e decretos relacionados ao tema são referências importantes nos estudos investigados.

Palavras-chave: Surdez; Políticas Públicas; Redes Sociais. 


\section{ABSTRACT}

http://dx.doi.org/10.5902/1984686X31128

The public education policies play a fundamental role in the construction and implementation of scenarios where education is valued and focuses on the student and their rights as a social subject and in this perspective, it is important to know the discussions about the Education of the Subjects. The objective of this study is to characterize studies on deafness and its aspects in the Revista Educação Especial from 2000 to 2017. Of the 569 articles available on the magazine's website, sixty were selected for the construction of this work (Appendix 1). The reflections made from the material show the importance of carrying out studies that place the deaf as a social subject within a socio-historical cultural perspective, where bilingualism has the role of allowing communication between individuals and their cultural development. The analysis showed that the subject of the didactic material is one of the most present in the education of the deaf, as well as the inclusion and pounds. The set of laws and decrees related to the subject are important references in the research studies.

Keywords: Deafness; Public Policy; Social Networks.

\section{RESUMEN}

Las políticas públicas educativas tiene nun papel fundamental en la construcción y concreción de escenarios donde la educación sea valorada y tenga como foco central al alumno y sus derechos como sujeto social y en esta perspectiva es importante conocer las discusiones acerca de la Educación de Sordos. El presente artículo tiene como objetivo caracterizar los estudios acerca de las ordera y dels ordoen la Revista Educação Especial em el período de 2000 a 2017. Para ello, a partir de los 569 artículos que están disponibles em el sitio de la revista, se seleccionar on 60 artículos que tratan de esta temática (Apéndice 1). Se realizar on estudios a través de redes sociales para establecer interrelaciones entre palabras clave, autores, obras más referenciadas y también publicaciones por año. Las reflexiones hechas a partir de los análisis muestran la importancia de realizar estudios que posicionen al sordo como sujeto social dentro de una perspectiva socio, histórico-cultural donde el bilingüismo tiene el papel de possibilitar la comunicación entre los individuos y también su desarrollo cultural. El análisis permitió percibir que el tema materiales didácticos es uno de los más presentes cuando se refiere a la educación de sordos, así como inclusión y libras. Se percibiótambién que el conjunto de leyes y decretos relacionados al tema son referencias importantes en los estudios investigados.

Palabras clave: Sordera; Políticas públicas; Redes sociales.

\section{Introdução}

A aceitação às diferenças e o atendimento às necessidades de cada indivíduo de forma que todos os cidadãos possam viver socialmente, economicamente e politicamente sendo respeitados e tendo lugar de fala, é um dos objetivos de 
desenvolvimento social presente em diversos grupos que compõe a sociedade e que se encontram manifestados em algumas políticas públicas.

Se entendermos a política pública como instrumento político e de governo no que pretende atender ás necessidades da sociedade, deveremos fechar um interessante e moderno "circulo virtuoso do poder social": a sociedade democrática, no exercício do voto, escolhe os dirigentes dos poderes Legislativo e Executivo como seus representantes, e esses produzem políticas públicas que retornam ao cidadão na proteção e execução de seus direitos. (CHRISPINO, 2016, p. 30)

Assim, CHRISPINO (2016) destaca a importância das políticas públicas na organização social de um país e nesse mesmo sentido podem-se fazer recortes mais direcionados a políticas públicas educacionais que advém de pensamentos mais amplos em termos de políticas públicas. Como por exemplo, quando a Lei de Diretrizes e Bases da Educação Brasileira (LDB) no 9.394, de 20 de dezembro de 1996, inaugura um capítulo para a Educação Especial. Tal fato pode representar a relevância do tema no conjunto da educação e um destaque nas prioridades das politicas públicas educacionais.

Nesse sentido, a LDB 9.394/96 (BRASIL, 1996) em seu artigo 4 inciso III classifica, genericamente, os grupos sociais que devem ser atendidos pela modalidade de educação denominada Educação Especial, a saber: crianças que apresentam deficiência mental, física, auditiva, visual ou múltiplas; crianças que são portadoras de condutas típicas; crianças de Alto Risco e crianças portadoras de Altas Habilidades. Mas, especificamente nos artigos 58, 59 e 60 da LDB nำ9394/96, que se referem à Educação Especial evidencia-se um destaque as características dessa modalidade de ensino e suas especificidades quanto a metodologias, adaptações curriculares, formação de professores dentre outras questões que tangem a esse atendimento especializado.

Os artigos citados da LDB trazem luz à equidade como princípio de atendimento educacional a todas as crianças, fato que é reforçado no Estatuto da Criança e do Adolescente (Lei no 8.069, 1990), em seu artigo 53, que enfatiza uma educação para e pelo desenvolvimento pessoal.

Tanto o Desenvolvimento quanto os Direitos Humanos estão diretamente relacionados aos princípios de liberdade. Trata-se de garantir que o indivíduo esteja livre de necessidades, violências, discriminações e livre para organizar-se, colocar-se, tomar 
http://dx.doi.org/10.5902/1984686X31128

decisões nos níveis social, político e pessoal (dentro das expectativas dos Direitos). Na esfera do desenvolvimento humano, a liberdade está expressa no processo de ampliação de oportunidades e opções dadas a esse indivíduo para que ele possa, de fato, desenvolver seus potencias. (SENNA, 2004, p.15, grifos do autor)

Diante desse cenário, gostaríamos de realizar um destaque a Educação de Surdos, onde o Decreto no 5.626 de 22 de dezembro de 2005 garante o direito á Educação das Pessoas Surdas ou com Deficiência Auditiva e regulamenta as leis nำ10.436, de 24 de abril de 2002, que dispõe sobre a Língua Brasileira de Sinais Libras e o artigo 18 da Lei no 10.098 de 19 de dezembro de 2000, que estabelece critérios básicos para promoção da acessibilidade de pessoas com deficiência.

A Educação de Surdos no Brasil apresenta três abordagens filosóficas, sendo a primeira e a segunda bem delineadas e a terceira em fase de transição. Os estudos de Quadros (1997) destacam que, a primeira abordagem, conhecida como oralista tinha como objetivo "recuperar" o surdo por meio do desenvolvimento da língua oral. A segunda abordagem é conhecida como Comunicação Total, onde há o uso da língua de sinais para desenvolver a linguagem da criança surda, mas esses sinais ancoramse na estrutura da língua portuguesa. Por fim, a terceira abordagem, ainda em transição, salienta a importância da educação bilíngue para surdos, onde se dá destaque a Libras como língua de instrução, de interação e identitária para os surdos, sendo o ensino da Língua Portuguesa ministrado como segunda língua para esses discentes (QUADROS, 2015).

Nessa abordagem de ensino, a surdez é percebida como diferença linguística, social e cultural (SKLIAR, 1997, 2006), imperando assim a visão sócioantropológica da surdez.

Quadros (1997) destaca que "muito além de um problema educacional, nos encontramos diante de um problema social, entre maioria e minoria, análogo aos problemas sociais enfrentados pelas comunidades indígenas no Brasil" (p. 26). Dessa forma, fica evidente que se trata de uma questão que envolve dimensões culturais e sociais, pois a maneira pela qual o indivíduo surdo se constrói sujeito social está fundamentada na maneira pela qual ele se comunica com o mundo e isso se dá unicamente pela linguagem, seja qual for a sua matriz, que no caso dos surdos é gesto-visual. 
http://dx.doi.org/10.5902/1984686X31128

As marcas do oralismo na educação de pessoas surdas vigoram e não são apagadas. A suposta superioridade da língua oral-auditiva sobre a língua visual-espacial, a partir do conhecido Congresso de Milão deixou marcas inapagáveis na história de bastantes adultos surdos. $O$ juízo foi transmitido e não reexaminado, embasando o preconceito e fazendo muitos ouvintes - inclusive professores - agirem em direção a uma tentativa de abolição, negação ou recusa da língua de sinais, por ser vista, não raramente, como prejudicial ao desenvolvimento de pessoas surdas. Imigrantes, indígenas e outros membros de minorias linguísticas também podem sofrer com o silenciamento e tentativa de apagamento de sua língua, mesmo sendo esta de modalidade oralauditiva, diferente do caso das pessoas surdas sinalizadoras, as quais têm sua L1, frequentemente associada à mímica, por exemplo. Tal não tem ocorrido às línguas de outras minorias, o que coloca o grupo surdo em um patamar diferenciado nesse silenciamento e apagamento. (PEREGRINO, 2015, p. 101)

Lima, Sampaio e Ribeiro (2015) problematizam a educação de surdos em uma concepção bilíngue sob a visão do sujeito surdo numa perspectiva histórico-cultural e evidenciam que esse bilinguismo advém de lutas dos surdos pelos seus direitos e reconhecimento cultural e linguístico.

Ao considerar a Surdez uma particularidade cultural, Kelman (2015) defende que a surdez atualmente é classificada assim por se encontrar num contexto multicultural, onde se preconiza o respeito pelas minorias e a garantia dos direitos humanos. $E$ destaca que os processos culturais são construídos socialmente e por meio de signos, sendo esses verbais, sonoros ou imagéticos.

Ao adquirir a linguagem, o homem utiliza-se dos signos verbais para referir-se a algo, ainda que ausente, iniciando-se, assim, o pensamento abstrato, conceitual. É através dos signos, integrantes dos processos interacionais e comunicativos entre os homens, que a cultura tem a sua origem. A atividade humana é mediada por signos, incluindo linguagem, sistemas de contagem, gráficos, trabalhos de arte, mapas, etc. Esses "meios semióticos" são tanto instrumentos que facilitam a construção coletiva do conhecimento, quanto os próprios meios de internalização que vão auxiliar o desenvolvimento de pensamento autônomo, crítico e criativo. (KELMAN, 2015, p. 55)

Com isso, Kelman (2015) destaca a importância da utilização de signos que permitam ouvintes e surdos realizarem processos de comunicação, evidenciando assim a importância do bilinguismo para que as interações sociais sejam realizadas e os sujeitos não sejam privados de um desenvolvimento linguístico e consequentemente a construção cultural.

No mesmo sentido, Skliar (2016, p. 30) defende que estudos surdos são "territórios de investigação educacional e de proposições políticas", uma vez que os 
http://dx.doi.org/10.5902/1984686X31128

conhecimentos sobre a surdez e o surdo são compostos por relações de elaborações indentitárias, linguísticas, culturais e comunitárias. Sendo assim, o autor sugere que as problematizações são necessárias e não versam sobre ponto de vista de surdos, mas sim de ouvintes e suas representações sociais do sujeito surdo.

Nesse sentido, os Estudos Surdos problematizam justamente aquilo que em geral não é problematizado, nem na educação especial, nem em outras abordagens dessa temática. O nosso problema, em consequência, não é a surdez, não são os surdos, não são as identidades surdas, não é a língua de sinais, mas, sim, as representações dominantes, hegemônicas e "ouvintistas" sobre as identidades surdas, a língua de sinais, a surdez e os surdos. Desse modo, a nossa produção é uma tentativa de inverter a compreensão daquilo que pode ser chamado de "normal ou cotidiano". (SKLIAR, 2016, p. 30)

Com isso, realizar esquadrinhamentos sobre a surdez e o surdo requer de investimento em estudos sobre os movimentos de aproximação e distanciamento entre a Educação Especial e a Educação de Surdos. Tal fato ocorre porque os surdos em suas lutas políticas vêm ganhando lugar de fala e por meio da Feneis ${ }^{1}$ vem conseguindo desenhar políticas públicas que retiram esses sujeitos de lugares de discussão de deficiência e de inclusão, que carregam estigmas de subproduto da educação (ALBRES, 2010).

Ao realizar considerações sobre o campo de políticas públicas educacionais, Jakimiu (2016) destaca a complexidade das trajetórias percorridas por essas políticas desde a sua criação, por meio da Legislação Educacional, até aos modos de operacionalização, através de Programas e/ou Ações Educacionais que objetivam trazer materialidade as políticas públicas. Assim, as publicações científicas relacionadas ao cenário surdo podem dar horizontes sobre o que vem sendo discutido no âmbito da teoria e da prática por pesquisadores.

Dessa forma, o presente trabalho tem como objetivo geral caracterizar a área de Educação de Surdos a partir das publicações referentes ao tema contidas na Revista Educação Especial no período de 2000 à 2017. Para isso, foi necessário realizar um mapeamento do universo dos artigos mostrando a representatividade dos temas pertencentes ao cenário surdo, por ano de publicação, por palavras-chave e por co-

\footnotetext{
${ }^{1}$ Federação Nacional de Educação e Integração dos Surdos. Disponível em :<http://feneis.org.br/> Acesso em: 26.nov.2017.
} 
http://dx.doi.org/10.5902/1984686X31128

autoria. Realizou-se também um estudo a respeito das principais referências bibliográficas utilizadas nessas produções.

A Revista Educação Especial é uma publicação científica direcionada a temas relacionados à Educação Especial na sua pluralidade. No que se refere à perspectiva surda, frequentemente estão presentes artigos abordando os múltiplos cenários onde a Educação de Surdos está presente, como por exemplo, intérpretes de Libras, bilinguismo e implante coclear.

Assim, acredita-se que realizar um mapeamento de temas relacionados à Educação de Surdos pode auxiliar na construção de um cenário que reunirá elementos relevantes nas pesquisas educacionais que foram publicadas nesse periódico que é uma das referências na área da Educação Especial sendo qualificada como A2 na área de Ensino e na área da Educação na avaliação de produções científicas realizada pela Coordenação de Aperfeiçoamento de Pessoal de Nível Superior (CAPES) no quadriênio de 2013 a $2016^{2}$.

\section{Método}

Foi realizado um estudo no universo dos artigos da Revista Educação Especial que estão disponibilizados on-line. No site desse periódico encontram-se 46 volumes contendo um total de 569 artigos científicos.

Para selecionar os artigos que abordavam o cenário surdo, foi analisado o título, o resumo e as palavras-chaves, o que gerou uma base de dados composta por 60 artigos científicos, no período de 2000 a 2017.

Algumas informações como título, ano de publicação, palavras-chaves autores, instituições de vínculo e referências bibliográficas foram extraídas de cada um dos artigos selecionados e organizadas em tabelas de acordo com estudos de catalogação e tratamento de dados, conforme rotinas estabelecidas pelo grupo de pesquisa que se utiliza desta ferrramenta (CHRISPINO, ALBUQUERQUE e COUTINHO, 2015; CHRISPINO et al., 2013a, 2013b; ROCHA et al., 2017; dentre

2 Avaliação realizada pela (CAPES), Disponível em:

$<$ https://sucupira.capes.gov.br/sucupira/public/consultas/coleta/veiculoPublicacaoQualis/listaCo nsulta GeralPeriodicos.jsf> Acesso em: 26.nov.2017. 
http://dx.doi.org/10.5902/1984686X31128

outros)) Essa organização gerou planilhas, preenchidas manualmente, contendo informações nas seguintes categorizações: artigo e ano de publicação; artigo, coautores e instituições de vínculo; artigos e palavras-chave e artigos e referências bibliográficas.

Posteriormente, os dados foram inseridos em software de análise de Redes Sociais (NODEXL ${ }^{3}$ ) baseado nos estudos de Melo et al. (2016), de modo a estabelecer relações entre autores e palavras-chave.

\section{Resultados e Discussão}

A análise foi realizada num universo de 569 artigos publicados na Revista de Educação Especial no período de 2000 a 2017. A escolha desse período deve-se ao fato dos artigos estarem disponibilizados no site da revista.

De 2000 a 2004 a revista chamava-se Cadernos de Educação Especial e tinha periodicidade semestral, sendo assim, nesse período constam-se 8 números com um total de 74 publicações científicas. No período de 2004 a 2008, a revista já era chamada de Revista de Educação Especial e as publicações continuavam semestrais, reunindo assim 10 números com um total de 104 artigos. A partir de 2009 a revista tornou-se quadrimestral tendo 27 números com um total de 375 artigos científicos.

A revista também conta com uma prática denominada Aheadofprint, que tem como objetivo alargar a divulgação de conhecimento por meio da disponibilização de textos aprovados e que serão publicados em próximas edições. Nessa condição, existem atualmente 16 artigos.

Do universo de 569 artigos visitados, 60 artigos tratam de temas relacionados a surdos e a surdez. Esses artigos foram selecionados levando em conta seus títulos, resumos e palavras-chave, a partir de consulta utilizando os descritores: surdo, surdez, Libras, Língua Brasileira de Sinais, Intérpretes, Deficientes Auditivos, Surdocegos.

No gráfico 01 é apresentada uma comparação entre todos os artigos publicados por ano e os artigos que tratam da surdez. Em 2006 não houve nenhuma publicação

${ }^{3}$ Disponível em :<https://nodexl.codeplex.com/> Acesso em: 08.nov.2017. 
http://dx.doi.org/10.5902/1984686X31128

referente ao tema em questão. Esse cenário mostra a representatividade do tema em todos os outros anos, em alguns de forma bem discreta em outros como 2015 e 2016 em maior número.

Gráfico 01 - Publicações por ano: todos os artigos x artigos abordando surdez

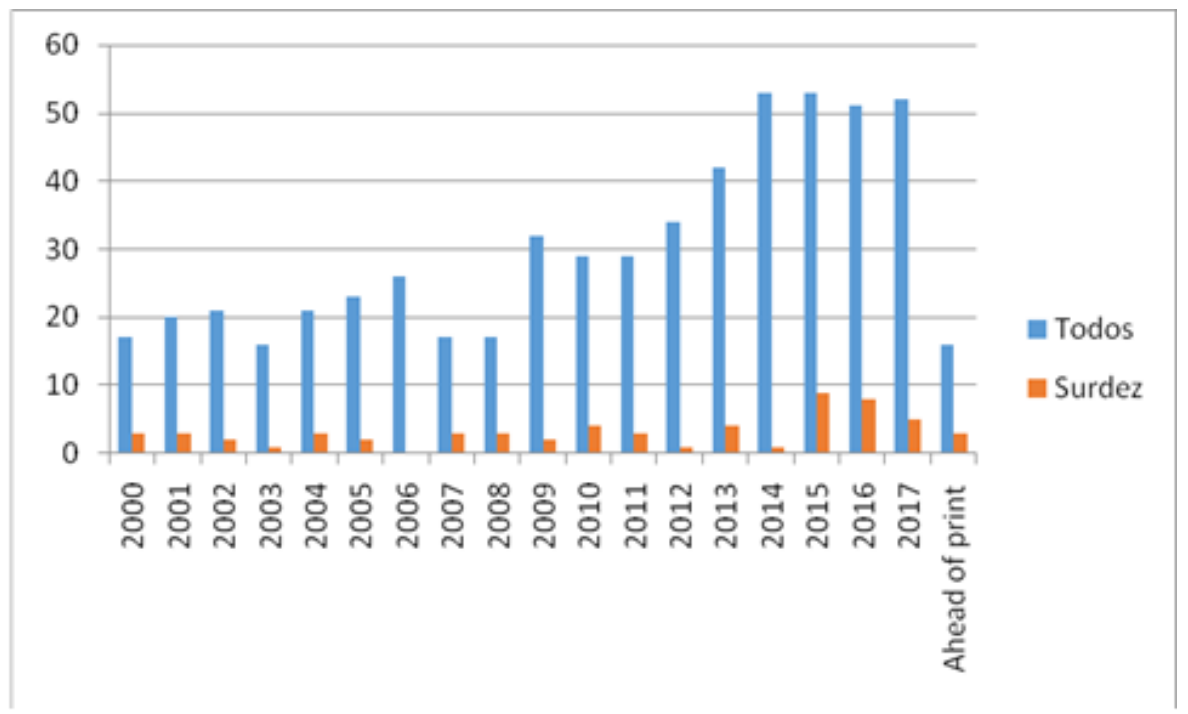

Fonte: Elaboração própria.

O gráfico 02 mostra a distribuição das publicações sobre a surdez por ano, percebe-se assim o número de publicações em cada época. Do total de 60 artigos, 9 foram publicados nos Caderno e 51 na Revista. Nota-se um aumento de publicações nos anos de 2015 e 2016, o que sugere a necessidade de estudos posteriores que expliquem tal mudança positiva.

Gráfico 02 - Publicações por ano.

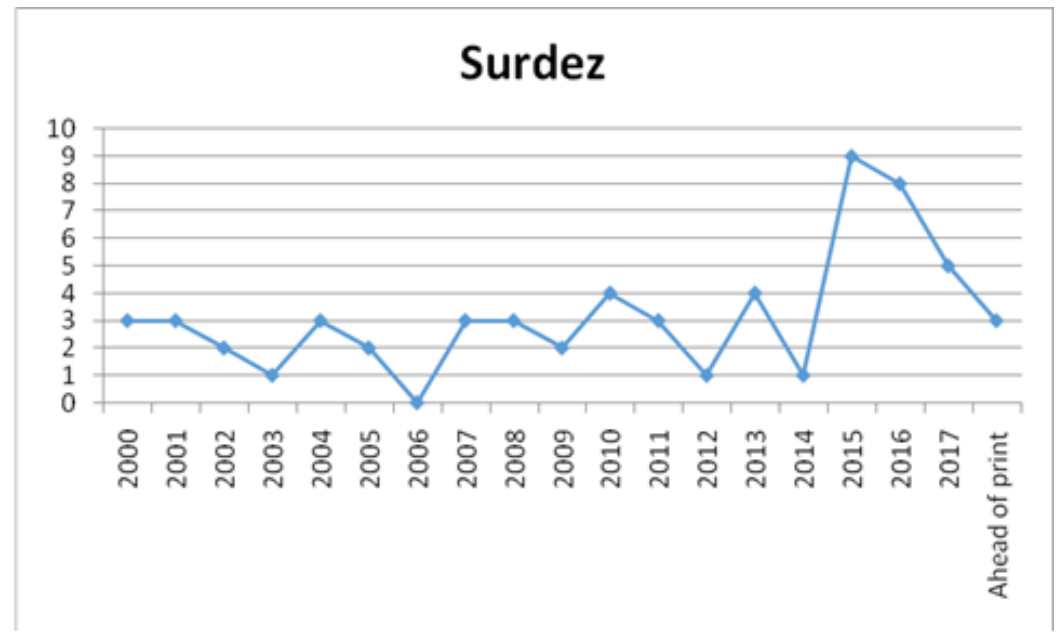

Fonte: Elaboração própria. 
Realizamos também uma categorização dos artigos de acordo com o tema principal abordado de modo a caracterizar os assuntos mais presentes nos 60 artigos que abordavam a temática da surdez. Essa categorização está ordenada na tabela 01.

Tabela 01 - Principais temas

\begin{tabular}{|c|c|}
\hline Tema & Frequência \\
\hline Materiais didáticos & 9 \\
\hline Inclusão & 8 \\
\hline Libras & 6 \\
\hline Educação Especial & 5 \\
\hline Identidade Surda & 5 \\
\hline Intérpretes & 4 \\
\hline Surdocegueira & 4 \\
\hline Currículo & 3 \\
\hline Cultura Surda & 3 \\
\hline Formação Docente & 3 \\
\hline Subjetividade do surdo & 3 \\
\hline Bilinguismo & 2 \\
\hline Implante Coclear & 2 \\
\hline Família & 1 \\
\hline História Surda & 1 \\
\hline Indicadores Sociais & 1 \\
\hline
\end{tabular}

Fonte: Elaboração própria.

Para a construção da rede social com as palavras chaves contidas nos artigos realizamos algumas aproximações que consideramos oportunas. Palavras como "alunos surdos", "aluno surdo", "surdo" e "surdos", que estão fazendo referência ao sujeito aprendente surdo foram substituídas por surdos, e assim fizemos com outras palavras, como "Libras" e "Língua Brasileira de Sinais", optamos por utilizar a Língua Brasileira de Sinais. No entanto, para língua de sinais e língua brasileira de sinais, acreditamos que não é possível essa aglutinação, pois existem várias línguas de sinais onde a língua de sinais brasileira é apenas uma delas, dessa forma, para saber se o valor semântico é o mesmo, teríamos que ler na integra todos os artigos que possuíam essas palavras como uma das palavras-chave.

Um total de 100 palavras-chave diferentes deram origem a uma rede social onde ficou evidente a representatividade da Surdez, do Surdo, da Educação Especial, da Inclusão, da Educação de Surdos e da Língua Brasileira de Sinais. O que nos leva a crer que a discussão sobre o cenário surdo perpassa por esses temas tanto na 
http://dx.doi.org/10.5902/1984686X31128

Educação Básica como no Ensino Superior, como foi sinalizado nos artigos selecionados. As frequências de palavras chaves na pesquisa são indicadas na tabela 2:

Tabela 02 - Principais palavras-chave

\begin{tabular}{|c|c|}
\hline Palavra-chave & Frequência \\
\hline Surdo & 17 \\
\hline Educação de Surdos & 8 \\
\hline Surdez & 8 \\
\hline Educação & 7 \\
\hline Educação Especial & 7 \\
\hline Inclusão & 6 \\
\hline língua de sinais & 5 \\
\hline bilinguismo & 3 \\
\hline deficiência auditiva & 3 \\
\hline educação inclusiva & 3 \\
\hline 14 palavras chaves & 2 \\
\hline 71 palavras chave & 1 \\
\hline
\end{tabular}

Fonte: Elaboração própria.

Figura 01 - Rede de palavras-chava

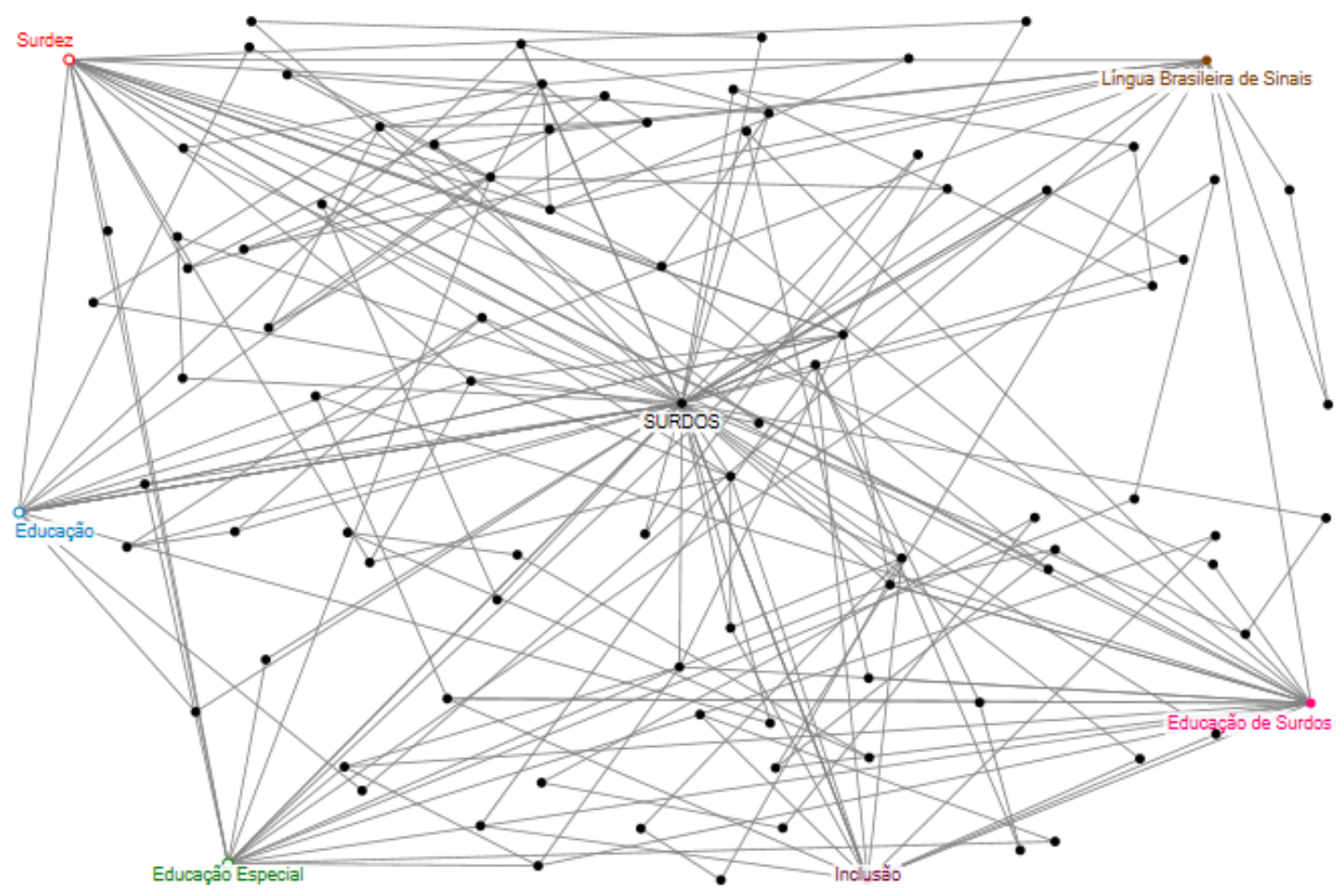

Fonte: Elaboração própria. 
http://dx.doi.org/10.5902/1984686X31128

Outra consideração que merece destaque é a presença, bastante discreta de temas relacionados ao intérprete e sua atuação na educação de surdos, o olhar sobre esses sujeitos traz questões relativas à formação, prática e seu papel na educação de surdos. A presença desses sujeitos é muito importante uma vez que o professor pode não ser fluente em Libras, o que impede a comunicação com o surdo. Por outro lado, pode haver algumas interferências na comunicação, uma vez que o trabalho do interprete pode não ser transcrição literal para a Libras e o seu possível desconhecimento conceitual da disciplina pode gerar comunicações não tão fieis ao sentido que o professor quer enfatizar. Com isso, trata-se de um tema muito discutido atualmente em eventos da área ${ }^{4}$, porém não se encontra presente de maneira significativa no corpus analisado, um fato que merece de investigações mais aprofundadas.

Quanto aos autores, ao listar os 110 autores e autoras percebeu-se que eles trabalham de forma isolada ou aos pares, o que não permite a formação de redes de coautoria, exceto para Lebedeff, Thoma, Kelman e Rocha que, individualmente são responsáveis por estabelecer a conexão entre dois artigos, cada um. Este fato pode indicar que a área possui baixa interação quando analisada pela ótica da produção coletiva ou por meio de rede de colaboração.

Ao realizar uma análise nas referências identificamos um total de 969 referências, sendo possível percebe que as obras mais citadas são de autores que trabalham com questões referentes a linguagens são recorrentes. A legislação brasileira referente à inclusão, surdos e Libras também aparece com frequência. Autores que não tratam a surdez como deficiência são os mais citados. Dessa forma, percebe-se que o quadro de referências vai ao encontro da ideia de traçar um cenário em que a surdez é uma especificidade e deve ser encarada de forma a posicionar o sujeito surdo em discussões que envolvam aspectos sociais, históricos e culturais.

\footnotetext{
${ }^{4}$ COINES, 2017 Disponível em :< https://acessibilidadeemmaos.wordpress.com/2017/10/18/coines2017/> Acesso em 23.jan.2018.; Fóruns Bilíngues, Disponível em:< http://www.ines.gov.br/forumbilingue> Acesso em 23.jan.2018
} 
Tabela 03 - Principais Referências

\begin{tabular}{|l|c|}
\hline \multicolumn{1}{|c|}{ Referência } & Frequência \\
\hline $\begin{array}{l}\text { BRASIL. Decreto no5.626. Regulamenta a Lei no 10.436, de 24 de abril } \\
\text { de 2002, que dispõe sobre a Língua Brasileira de Sinais - Libras, e o art. } \\
\text { 18 da Lei no 10.098, de 19 de dezembro de 2000 }\end{array}$ & 14 \\
\hline $\begin{array}{l}\text { BRASIL. Lei no 10.436. Dispõe sobre a Língua Brasileira de Sinais - } \\
\text { Libras e dá outras providências }\end{array}$ & 13 \\
\hline $\begin{array}{l}\text { SKLIAR, C. (Org.). A surdez: um olhar sobre as diferenças. 4 ed. Porto } \\
\text { Alegre: Mediação, 2010. }\end{array}$ & 12 \\
\hline $\begin{array}{l}\text { BRASIL. Lei no 9.394/96. Lei de Diretrizes e Bases da Educação } \\
\text { Nacional. }\end{array}$ & 11 \\
\hline $\begin{array}{l}\text { QUADROS, R. M. de. Educação de surdos: efeitos de modalidade e } \\
\text { práticas pedagógicas. 2004. }\end{array}$ & 9 \\
\hline $\begin{array}{l}\text { BRASIL.Política Nacional de Educação Especial na Perspectiva da } \\
\text { Educação Inclusiva. Documento elaborado pelo Grupo de Trabalho } \\
\text { nomeado pela Portaria Ministerial no 555, MEC/SEESP, de 5 de junho de } \\
\text { 2008. }\end{array}$ & 8 \\
\hline $\begin{array}{l}\text { GOLDFELD, M. A criança surda: linguagem e cognição numa } \\
\text { perspectiva sociointeracionista. São Paulo: Plexus, 2002. }\end{array}$ & 8 \\
\hline $\begin{array}{l}\text { VYGOTSKY, L S. Pensamento e linguagem. São Paulo: Martins } \\
\text { Fontes, 1991 }\end{array}$ & 8 \\
\hline $\begin{array}{l}\text { SACKS, O. Vendo vozes: uma jornada pelo mundo dos surdos. } \\
\text { Rio de Janeiro: Imago, 1998. }\end{array}$ & 7 \\
\hline $\begin{array}{l}\text { VYGOTSKY, L. S.A formação social da mente. São Paulo: } \\
\text { Martins Fontes, 1998. }\end{array}$ & 7 \\
\hline
\end{tabular}

Fonte: Elaboração própria.

\section{Considerações Finais}

O papel das políticas públicas em prol da Educação de Surdos é de fundamental importância uma vez que ampara e fomenta discussões e praticas a respeito do lugar social desses sujeitos. Principalmente a lei no 10.436/2002 que regulamenta a Libras como primeira língua dos surdos e permite que esses sujeitos se desenvolvam linguisticamente em sua língua natural e assim posicionando o Brasil como país bilíngue tendo a Língua Portuguesa e a Língua Brasileira de Sinais (Libras) como línguas oficiais.

A construção de redes sociais a partir dos 60 artigos que tratam do cenário surdo da Revista Educação Especial nos possibilita realizar algumas reflexões sobre a importância de olhares para as questões linguísticas, culturais, sociais e históricas dos surdos, posicionando assim a surdez como uma especificidade linguística e não como uma deficiência física. 
http://dx.doi.org/10.5902/1984686X31128

Essa aproximação permite algumas aderências a discussões sobre multiculturalismo e direitos humanos, onde minorias são tratadas a partir de suas características culturais, ou seja, como grupo social em que os indivíduos atuam construindo socialmente os espaços de significação.

Assim, a linguagem dos surdos não se limita a processo de comunicação entre os pares e os demais indivíduos presentes na sociedade, mas como processo cognitivo uma vez que o seu desenvolvimento permite articulações que desencadeiam no desenvolvimento cultural e na percepção do mundo a sua volta. Tal fato é evidenciado pela constante presença de Vygotsky nas referências dos artigos, de maneira geral fazendo alusão a processos de mediação entre o homem e o mundo.

O trabalho permitiu conhecer como é a representatividade da surdez e do surdo na Revista Educação Especial no período de 2000 a 2017, bem como realizar um mapeamento dos principais autores e seus temas de estudo. Contudo é importante frisar que não pretendíamos realizar uma análise profunda dos temas e problematizalos, mas sim traçar cenários que permitissem visões exploratórias e que mostrassem interrelaçoes entre palavras-chaves e autores.

A análise de redes sociais aplicada ao tema permitiu a visão do conjunto da área e favorece a identificação de pontos fortes - que devem ser mantidos - e das lacunas existente - a solicitar ações que exprimam gestão eficaz da área na busca de melhores resultados para a comunidade. É, pois, um estado-da-arte descritivo e que realça as relações percebidas por meio do software e que permite - e exige - um desdobramento qualitativo dos artigos selecionados, das relações estabelecidas e das lacunas identificadas.

\section{Referências}

ALBRES, N. de A..Surdos \& Inclusão Educacional. Rio de Janeiro: Editora Arara Azul, 2010.

BRASIL. Decreto n-5.626. Regulamenta a Lei no 10.436, de 24 de abril de 2002, que dispõe sobre a Língua Brasileira de Sinais - Libras, e o art. 18 da Lei no 10.098, de 19 de dezembro de 2000. Disponível em :<http://www.planalto gov.br/ccivil 03/ ato2004-2006/2005/decreto/d5626.htm> Acesso em : 19.nov.2017.

BRASIL. Lei $\mathbf{n} \mathbf{0}$ 10.098. Estabelece normas gerais e critérios básicos para a promoção da acessibilidade das pessoas portadoras de deficiência ou com mobilidade reduzida, 
e dá outras providências. Disponível em :<http://www. planalto.gov.br/ccivil 03/LEIS/L10098.htm\#art18> Acesso em: 19.nov.2017.

BRASIL. Lei no 10.436. Dispõe sobre a Língua Brasileira de Sinais - Libras e dá outras providências. Disponível em :<http://www.planalto.gov.br/ccivil 03/LEIS/2002/L10436.htm> Acesso em : 19.nov.2017.

BRASIL. Lei no 8.069/90. Estatuto da Criança e do Adolescente. Disponível em: $<$ http://www.planalto.gov.br/ccivil 03/leis/L8069.htm>Acesso em : 19.nov.2017.

BRASIL. Lei no 9.394/96. Lei de Diretrizes e Bases da Educação Nacional. Disponível em:<http://www.planalto.gov.br/ccivil 03/leis/L9394.htm> Acesso em: 19.nov.2017.

CHRISPINO, A. Introdução aos Estudos de Políticas Públicas: uma visão interdisciplinar e contextualizada. Rio de Janeiro: FAPERJ;FGV, 2016.

CHRISPINO, A.; ALBUQUERQUE, M. B.; COUTINHO DA SILVA, P. B.. Os vinte anos da Revista Ensaio analisados por meio de Redes Sociais.Ensaio: aval.pol.públ.Educ., Rio de Janeiro , v. 23, n. 86, p. 13-35, fev. 2015 . Disponível em <http://www.scielo.br/scielo.php?script=sci_arttext\&pid=S0104 $40362015000100013 \& \operatorname{lng}=p t \& n r m=i s o>$.

Acesso

em: 24 jan. 2018. http://dx.doi.org/10.1590/S0104-40362015000100001.

CHRISPINO, A.; LIMA, L.S.; ALBUQUERQUE, M.B.. Vendo CTS como rede: as publicações mais prestigiadas no Brasil. Enseñanza de las Ciencias, v. extra, p. 919923.2013b.

CHRISPINO, A.; LIMA, L.S.; ALBUQUERQUE, M.B.; FREITAS, A.C.C.; SILVA, M.A.F.B..A área CTS no Brasil vista como rede social: onde aprendemos? Ciência \& Educação, v. 19, n. 2, p. 455-479.2013a.

JAKIMIU, V. C.de L.Considerações acerca do campo disciplinar das políticas educacionais. Revista de Estudios Teóricos y Epistemolólogos em Política Educativa, v.1, n.2, pp.221-229, 2016.

KELMAN, C.A. Multiculturalismo e surdez: respeito às culturas minoritárias. In: LORDI, Ana Claudia Balieiro.; MÉLO, Ana Dorziat Barbosa de .; FERNANDES, Eulalia(Org.) Letramento, Bilinguismo e Educação de Surdos. 2ed. Porto Alegre: Mediação, 2015.

LIMA, C. M.; SAMPAIO, C. S..; RIBEIRO, T.. Apontamentos sobre a educação de Surdos: aprendizagens no encontro com a surdez. Revista Espaço. n.43, p. 89-110, jan./jun., 2015.

MELO, T. B.. et al. Os temas de pesquisa que orbitam o enfoque CTS: Uma análise de rede sobre a Produção Acadêmica Brasileira em Ensino. RBPEC. v. 16. n. 3. p. 587-606, 2016.

PEREGRINO, G. S.. Preconceito contra surdez e a Libras: alunos surdos rompem o silenciamento. In: ANDRADE, M.(Org.) Diferenças Silenciadas: pesquisas em educação, preconceitos e discriminações. Rio de Janeiro: 7 Letras, 2015. 
http://dx.doi.org/10.5902/1984686X31128

QUADROS, R. M. Educação de surdos: a aquisição da linguagem. Porto Alegre: Artmed, 1997.

QUADROS, R.M. O "BI" em bilinguismo na Educação de surdos. In: LORDI, Ana Claudia Balieiro.; MÉLO, Ana D. B.; FERNANDES, E.. (Org.) Letramento, Bilinguismo e Educação de Surdos. 2ed. Porto Alegre: Mediação, 2015.

ROCHA, M. L.; GONZALEZ, A. H. G.; BRUNO, N. V.; CHRISPINO, A. (2107). Representatividade da Biologia em CTS Por Meio de Análise por Redes Sociais. Contexto \& Educação, ljuí, RS, ano 32, n. 102, p. 81-99, maio/ago.SENNA, V. Introdução. In: ANDRÉ, S.;COSTA, A.C.G. Educação para o Desenvolvimento Humano. São Paulo: Saraiva: Instituto Ayrton Senna, 2004.

SKLIAR, C. Os Estudos Surdos em Educação: problematizando a normalidade. In: SKLIAR, C. (Org.) A surdez: um olhar sobre as diferenças. 8ed. Porto Alegre: Mediação, 2016.

SKLIAR, C.(Org.).Educação \& Exclusão: abordagens socioantropológicas em educação especial. Porto Alegre: Mediação, 1997.

\section{Correspondência}

Renata Barbosa Dionysio - Universidade Federal do Tocantins - Campus Araguaína Av. Paraguai, esq. c/Rua Uxiramas, s/nํㅡ, Setor CIMBA. CEP: 77.824-838, Araguaína, TO, Brasil

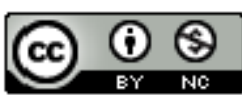

This work is licensed under a Creative Commons Attribution-NonCommercial 4.0 International (CC BY-NC 4.0) 